\title{
Ed overcrowding - matematic models for integrated solutions and decisions
}

\author{
LUCIANA TEODORA ROTARU, MIHAI BĂNICIOIU - COVEI \\ Emergency Department and First Aid, University of Medicine and Pharmacy Craiova, 2 Petru Rareș 200349, Craiova, Dolj
}

Corresponding author

Luciana Rotaru

Emergency Department and First Aid

University County Hospital Craiova

Tabaci St. No. 1, zip code 200642, Dolj County

Phone: +40722702989

E-mail: lucianarotaru@yahoo.com

Dear Editor In Chief,

We are writing to You in line with an very interesting point of view regarding the Emergency Department (ED) development. The paper titled Improving Emergency Department Capacity Efficiency, published in your Journal 2016; 12(1): 5257 , as an original articles, spotlight solution for ED crowding.

So we are proposing a mathematics models for reciprocal accommodation of patients flows to the response capacity of the ED.

ED overcrowding is not just a reality but a huge problem, not only on satisfaction of staff and patients, but also in terms of ED performance. It is already known that, prolonged stay in ED is associated with lower compliance of ACC rules for care of ACS/ NSTEMI (1) and increased mortality for hospitalized patients. $(2,3)$

Theoretically, there are two possible approaches: modulating demand (categorization and stratification of entries, triage, types and volume of auxiliary resources patients, use bifocal FastTrack for reducing time of wait) or enhancing capacity.

Managing resources to meet demand.

Limiting resources, constraint, (4) implies a capacity below the request, that must satisfy (available imagistic investigations, surgery room, ICU (intensive care unit) ventilation capacity) (5) and only change of limiting resources will improve the flow. The mathematical study of waiting lines was our model for predicting how systems serving random arrivals behave.

The flow of patients in the ED can be compared as an ordinary elementary stream flow, stationary and independent, called "Poisson type flow" (the occcured flow can be calculated by Poisson distribution law). To an elementary strem flow we can apply Pearson's test of validation of probabilities for arrival of patients flow and time until patients are admitted.

Applying simulation of this type for such a process is recommended by the fact that ED are systems with a large number of workstations with complex topology, the time of patients arrival is complicated and with mixtures of distributions, there is prioritization and pursuing efficiency targets. The system of patients admitting can be recalibrated if some data are known: arivals distribution and duration of work per patient, as random or deterministic variables, number of workstations, approach algorithme, system capacity.

It is important from the beginning if the ED is considered as an closed system, an open system with infinite source of workstations with refusal, (for improvement, number of workstations should be increased), open systems (a number of patients waiting). or open system with limited number of stations (no refusal).

High rates of use in systems with many variations generates very long periods of waiting. In high level of usage, small changes can dramatically affect user waiting time, both in good or bad way. A small change could be represented by the increase of minimum workstations, but mathematically if only number of service providers increases, also waiting time will increase exponentially.

Conclusion is that modeling results depend on how emergency system is interpreted and placed in the typology of queuing systems, then to realize analytical study for distribution of time between presentations and admitting time, patient approach policies, and than can be deduced mathematical formulas of efficiency factors of the system.

Key words: Emergency Department, overcrowdind, Poisson flow, Pearson's test, constraint, ED capacity

\section{REFERENCES}

1. Diercks DB, Roe MT, Chen AY, Peacock WF, Kirk JD, Pollack CV Jr, et al. Prolonged emergency department stays of non ST - segment elevation myocardial infarction patients are associated with worse adherence to the American College of Cardiology/American Heart Association guidelines for management and increased adverse events. Ann Emerg Med 2007 Nov;50(5):489-96.

2. Richardson DB. Increase in patient mortality at 10 days associated with emergency department overcrowding. Med J Aust 2006 Mar 6;184(5):213-6.

3. Chalfin DB, Trzeciak S, Likourezos A, Baumann BM, Dellinger RP. Impact of delayed transfer of critically ill patients from the emergency department to the intensive care unit. Crit Care Med 2007 Jun;35(6):1477-83.

4. Goldratt EM, Cox J. The theory of constraints. The goal. 4th ed. Great Barrington, Massachusetts. The North River Press Publishing Corporation. 2014. p. 362.

5. Rapid JG, Perondi B, Dias RD, Miranda LC, Cohen C, Carvalho CR, et al. Development of an algorithm to aid triage decisions for intensive care unit admission: a clinical vignette and retrospective cohort study. Crit Care 2016 Apr 2;20(1):81. doi: 10.1186/s13054-016-1262-0. PMID: 27036102 